$\xi=\mathrm{\alpha}$

\title{
Comparison of patient safety culture among psychiatric, general, and specialized hospitals of Tehran
}

\author{
Pouran Raeissi ${ }^{1}$, Erfan Shakibaei $^{2} *$ \\ ${ }^{I}$ PhD. Faculty of health management, school of health management and information sciences, \\ Iran university of medical sciences, Tehran, Iran \\ ${ }^{2}$ M.S. Faculty of management sciences and health economic ,Tehran University of Medical Sciences, Iran \\ *Corresponding author E-mail: e-shakibaeib@razi.tums.ac.ir
}

\begin{abstract}
Patient safety culture (PSC) has been considered less than its significance within high risk health care facilities so far. The aim of this study was to firstly compare PSC among psychiatric, general, and critical/intensive care systems then, focus on common weaknesses between Middle East countries. The study design was cross-sectional which was executed by using of a two stage sampling frame. Researchers had 298 questionnaire completed $(\mathrm{RR}=62 \%)$ among three groups comprising nurses, nurse's aides, and laboratory personnel. The Farsi version of Hospital Survey on Patient Safety Culture (HSOPSC) questionnaire was employed in this study. Descriptive statistics, and One Way ANOVA were used aiming to analyze collected data by using of SPSS 20. The highest percent of composite mean scores in Specialized, Psychiatric, and Generals were 61.49\%, 56.67\%, and 55.69\% respectively. Common weakest dimensions of PSC among the three groups of hospitals included: Non-punitive response to error (24.3\%), Staffing (32.18\%), and Communication openness $(42.44 \%)$. There were no significant differences among means and variences of the three groups of hospitals. It can be concluded that health care systems may have no differences in PSC correspond to disparities in amount of risk and job pressure. An implication of this study is the possibility that PSC is mostly local, although some weaknesses between our study and Middle East seemed to be symmetrical.
\end{abstract}

Keywords: Critical Care; General; Intensive Care; Patient Safety; Psychiatric.

\section{Introduction}

Patient safety is described as "the freedom from accidental injury" (Kohn et al., 2000, p.4) [1] but, it does not specify the path by which safety flows into an organization. Singer et al. (2009) [2] believe that this path is "the values shared among organization members about what is important, their beliefs about how things operate in the organization, and the interaction of these with work unit and organizational structures and systems, which together produce behavioral norms in the organization that promote safety" (Singer et al., 2009, p.2). Patient safety culture (PSC) is the path including of health care personnel's values, notions, perceptions, attitudes, and routines about how they would practice regarding patients' lives and safety [3] [4]. It is a concept which has been framed in a wide range of industries including health care industry [5] [6], which generates from workers' perception through which they express how rules are practically established after being entered to organization and what is their reflect about everyday changes in work environment as well as that, act as a basis for demonstrating and anticipating professionals' behavior with regard to patient safety [7] [8].

Workplace Safety has been considered with the aim of reducing medical and non-medical errors from various standpoints [9], safe in the knowledge that different point of views within dormant and clear situations in which medical errors and accidents happens relating to workplace culture could be understood by assessment of safety culture [5]. Safety culture in the field of health care considers as a "leading indicator" so as to delivers necessary infor- mation to predict and impede potential risks [6]. Tracing safety culture to evidences of high risk situations with respect to professional's safety perception can introduce strengths and weaknesses of the organization to safety managers pertains to patient safety [10].

Safety culture has been identified as a cornerstone aiming to establish and develop patient safety plans [11]. Also according to regulations in some countries, industries dealing with high risk in their everyday procedures must assess safety culture of the organization frequently [12]. In addition, declaration of Joint Commission International (JCI) concerning policies, procedures, and processes of health care organizations in which suitable organizational culture had to be inserted, so that whole system move along with appropriate culture [13], are the principal proponent in order for drawing our attention to safety culture. On the other hand, a growing body of literatures has shown high rates of medical injuries and preventable death [14], including 50\% of adverse events substantiating this claim [15] [16]. Therefore, health care systems were ranked as high risk organizations, inasmuch as statistics of adverse effects and increasing complexity accompanying with these systems have been proving it thus far [6]. Hence, patient safety was identified as one of the most significant columns in quality of delivered care and if positive PSC exists at every entity of health care organizations, clinical and organizational performance will improve [13] [17] [18] [19] [20]. Positive culture affects on organizations' internal communication, relationships between different and same levels of responsibilities, workers' trustworthy feeling with purpose of increasing in reports with regard to adverse events to upper level supervisors and improving of pivotal medical error 
lessons [21] [22]. Unlike medical interventions, organizational interventions relating to manner of workforce need lots of deep attitudinal changes in order to achieve acceptable results [17]. In spite of the fact that health care workers provide the best care to which they are able, still many errors exist in virtue of interactional nature of human and organizations [23]. Given that, effects of professionals with the intention of alleviating adverse events make safety culture a main factor in development of patient safety [14]. In line with PSC having been considered as a key role player in quality of care, a vacuity of health care workers' compliance with patient safety standards associated with safety culture has been felt [24] [25] [26]. Accordingly, adapted education to PSC was injected into professionals' education courses in many countries [27] [28] [29].

Among service delivery systems, hospitals face to a countless complexity pertains to work environment, multiple decentralized work units, various top managers among which the power of decision making is divided, and convoluted rigid rules accompanying with regulations which must be considered along with the way of delivering health care services. In such places, professionals could potentially kill people or get killed in light of the knowledge that they ought to learn and treat simultaneously. In one hand, thoroughly organized health settings establish under supervision of solid rules and precise safety assurance protocols. In the other hand, hazardous unpredictable workplace from sights of both patients and health professionals delineate a contrast in health system as a safe workplace. Thus, attitudes, behaviors, and perception, which altogether constitute the culture of workplace, take effects from this contradictory condition [30].

Psychiatric patients cause a particular situation in psychiatric hospitals according to several special characteristic including unwilling hospitalization and aggressive behaviors which exist in nature of this type of patients. Secure in the knowledge that dangerous places, violence, sexual harassment, mal use of medical equipment are permanent characteristics of psychiatric hospitals, yet medical events count a major growing issue on the ground that policy makers and top managers of health settings disregarded this special nature in which dealing with hazardous and difficult patients [31], long time hospitalization, low job satisfaction, high usage of anti-anxiety and relaxing drugs is quotidian [32]. Another major high risk type of health settings appears in critical/intensive care units particularly within specialized hospitals. This group confronts a great volume of risk concerning patient safety in so far as every patient in this units is engaged at least in one preventable adverse event [33]. Not only patients in this units are extremely vulnerable more than other group of patients with respect to their health condition, but also medication errors happening in this units proved to be firmly lethal allied to nature of care within this units [34] [35]. The nature in which system disorders, problematic organizational factors, violation of medical protocols, distraction and disturbance in the meantime of delivering care, and deficiency of communication exists several times more than other types of healthcare settings [34].

A wide range of studies have argued that there are some disparities between definitions of safety climate and safety culture how safety climate includes perceptions of professionals about dimensions regarding safety. In contrast, safety culture alludes to manners, values, and notions when they impact on safety-related situations. Furthermore, there are some differences between measuring methods of safety climates and safety culture. In several studies have been recommended use self-report surveys in order for measuring safety climate [5] [36]. By contrast so as to measure safety culture has been recommended employ interview, observation, etc. [37] [38]. Nonetheless, these terms were considered interchangeably in many studies as the current study [39].

Safety culture has been noticed in various industries in order to frame some interventions for addressed gaps [17]. Meanwhile, WHO and many professional authorities have advocating for patient safety programs aiming for promoting patient safety condition [40] [41]. Toward assessing PSC and to address patient safety gaps the Agency for Health Care Research and Quality framed a helpful tool called Hospital Survey on PSC namely Hospital Survey on Patient Safety Culture (HSOPSC) [42], which has been employed in a wide spectrum of health care organizations [43] [44] [45] [46]. HSOPSC questionnaire divides to 3 part including Unite-level, Hospital-wide, and Outcome measures which these parts comprise 7,3 , and 2 dimension respectively.

A wide growing body of literature has been trying to assess PSC among various health care systems. Singer et al. (2003), in order to meet identification of differences between various workers with varied levels within organizations assessed safety culture. As a result, significant differences were recognized not only between the organizations, but also within types and levels of workers [47]. Go along with same purpose, Grant et al. (2006) in their study by investigating dimensions of PSC argued that physicians' perception were significantly different from other personnel regarding team work and most of staff did not think with regard to incident reporting in a positive way [48]. Meanwhile, Kim et al. (2007), draw our attention to a non-punitive culture additionally, by introducing subgroups of workers showed that nurses' perception concerning patient safety differ in a spectrum from front line nurses to older and high position nurses [46]. Like Kim et al. (2007), Hellings et al. (2010), expressed that different attitudes in relating to PSC exist between professional subgroups [49].

Hellings et al. (2007), like Grant et al. (2006), introduced "Teamwork within hospital units" dimension as one of the highest dimensional positive score ranked by personnel [45]. Also, similar to Grant et al. (2006), and Kim et al. (2007), they found "Nonpunitive response to error" as the lowest dimensional positive score among PSC dimensions [48] [45] [46]. In an evaluation of PSC, Chen \& Li (2010), in addition of demonstrating that health care staff think positively regarding patient safety, recognized some distinctive features in culture of workers thus, they considered this differences as nature of any different culture ; hence, depend on case adaptive changes on measurement tools would be necessary [50]. Ausserhofer et al. (2011), by highlighting nurses' perception with the aim of describing error reports and prevailing actions executing by nurses in hospital settings concluded that staff's behaviors with regard to adverse events and errors were established in a low level of PSC; further, attaching PSC with routine procedures and practices seems to be necessary [51]. A recent study by Ballangrud et al. (2012), aiming for studying registered nurses' perception in intensive care units suggested that there are some differences not only between hospitals, but also between types of ICUs with respect to PSC. Furthermore, "frequency of incident reporting", "feedback and communication about errors", and "organizational learning and continues improvement" has been considered as weaknesses [52]

A major body of researches has linked to PSC assessment so that, assessing the impact of PSC has been evaluated with varied goals. Nevertheless, noticeable lacking in assessing PSC so as to investigate status of discrepancies corresponds to PSC among various hospitals with different specialties exists and to pay attention in this regard seems noteworthy.

In the current study we aimed to compare status of PSC among psychiatric, general, and critical/intensive care units of specialized hospitals of Tehran so as to establish a baseline of variety of PSC among various care specialties for future plans and improvements in health care system of Iran.

\section{Methods}

In this study the instrument, Hospital Survey on Patient Safety Culture (HSOPSC), which was designed by the Agency for Healthcare Research and Quality has been employed aiming to measure hospital staff opinions about patient safety issues, medical errors and incident reporting in the targeted hospitals. [42] Validity and reliability of Farsi version of this questionnaire were measured by Javad et al. (2012). [53]

In the original questionnaire 18 out of 56 items were restructured in a negative way before survey initiation and after completion 
were recoded by researches for fallowing analysis after collecting the questionnaires.

Twelve hospitals were considered as the study sample and were divided into three groups, namely Psychiatric, General and Specialized with the intention of establishing a comparing frame of PSC between Psychiatric, General, and critical/intensive care in Specialized hospitals. Pursuing this aim, similar hospitals with respect to size ( $\leq 300$ beds) were determined and opted. As results 4 hospitals for each group remained in order to constitute our sampling frame.

In the second stage, targeted population was stratified into three subgroups, namely nurse, nurse's aide, and laboratory personnel. Regarding uneven proportion of nurses, nurse's aides, and laboratory personnel in hospitals, we calculated virtual amount of this disparity among personnel. As a result we discovered that approximately nurse's aides proportion constitutes one-third of nurses and lab personnel proportion is one-sixth of nurses in the study population. Therefore, we had 40 questionnaire distributed in the location of hospitals in the frame of stratified random sampling on the ground of population proportions. In sum, 298 completed questionnaire were received ( $\mathrm{RR}=\% 62)$ which among 298 participants 38.7, 31.1, and 30.2 attributed to percentage of participants in Specialized, General, and Psychiatric hospital groups respectively. Researchers built a categorization regarding positive scores which divided to five parts and named it cut-points. These five parts comprise $20 \%$ each of the total scores delineating scores of PSC from very strong position to very weak. Major proponent of building this structure for scores is that we wanted to categorize hospitals and dimensions of PSC precisely and distinctively in a wide spectrum. Scores and conditions within cut-points are showed in Table 1.

Table 1: Patient Safety Culture Grades in the Shape of Cut-Points

\begin{tabular}{ll}
\hline Cut points & Condition of patient safety culture \\
\hline $0 \%-20 \%$ & Very weak \\
$21 \%-40 \%$ & Weak \\
$41 \%-60 \%$ & Average \\
$61 \%-80 \%$ & Strong \\
$81 \%-100 \%$ & Very strong \\
\hline
\end{tabular}

All the participants were aware of study objectives and researchers received their informal consent in order for getting involved in the study. After collecting all the questionnaires, they were converted by employing SPSS20 software and also researchers utilized (HSOPSC) manual aiming to refine data [42].

Ethical approval did not seem to be necessary since any patient was not entailed in this study.

\section{Results}

\subsection{Responses and demographics}

From 480 questionnaires distributed in the investigated hospitals $(n=12) 310$ were completed and returned to the researchers and from which 298 questionnaires were identified as qualified questionnaire and were analyzed in this study. The overall response rate was $64.5 \%$. The Data were gathered between May and October 2014. Table 2 represents the demographic information of the respondents.
Table 2: Demographic Information of the Respondents

\begin{tabular}{lll}
\hline Variables & & Percentage \\
\hline \multirow{2}{*}{ Sex } & Male & 30.64 \\
& Female & 69.36 \\
Marital Status & Single & 34.68 \\
& Married & 65.32 \\
& Diploma & 8.78 \\
& Associate & 8.1 \\
Education & Bachelor & 69.59 \\
& Master & 6.8 \\
& Ph.D & .36 \\
& Student of medical sciences & 7.09 \\
& $30 \geq$ & 41.49 \\
Age & $31-41$ & 38.1 \\
& $41-51$ & 15.99 \\
& $51-61$ & 2.39 \\
Job & $61 \leq$ & 1.03 \\
& Nurse & 67.79 \\
Direct contact with patients & Nurse's aide & 20.01 \\
& Laboratory workers & 12.2 \\
& Yes & 82.04 \\
\hline
\end{tabular}

Percentage of respondents participated in the survey from psychiatric, specialized, and general hospitals were $30.2,38$, and 31.2 respectively.

\subsection{Mean positive scores (MPS) of patient safety culture}

In this study we employed the manual made for HSPOSC users in order for analyze and report the results of this survey. Thus, we transform answers which were based on Likert scale to MPSs whit the aim of express frequency of answer in each dimension (Sorra \& Nieva, 2004).

The highest percent of MPSs concerning dimensions of PSC given the sum total of 12 hospitals were attributed to 78.55 "Organizational learning-continuous improvement", 75.97 "Teamwork within the unit", and 70.72 "Executive management support for patient safety" which locate 12 hospitals at the strong position among the cut points in respective dimensions. The lowest percent of MPSs regarding the sum total of 12 hospitals included 24.3 "Non-punitive response to error", 32.18 "staffing", and 42.44 "communication openness" directing the first two of mentioned dimensions to the weak position and the last one to the average position among the cut points. The highest and lowest standard deviations were 15.57 allied to "Feedback and communication about error" dimension and 7.48 related to "Teamwork within the unit" dimension. Standard deviation (SD) and MPSs of the dimensions in 12 hospitals with regard to categorization of the questionnaire (i.e. Unit-level, Hospital-wide, and Outcome measures) are provided in Table 3 .

Concerning the total MPSs among the surveyed hospitals, the highest score were belonged to Sina hospital with $x=67.97 \%$ the lowest attributed to Cancer Treatment Center with $\mathrm{x}=46.16 \%$ (Table 3).

Majority of respondents (40.6\%) believed that patient safety grade in 12 hospitals was strong and $49.3 \%$ of respondents have not reported any error or adverse event to their superior authority in past 12 months. Descriptive analysis of total outcome measures for 12 hospitals is provided in Table 4. 
Table 3: Standard Deviation (SD) and MPSs of the Dimensions in 12 Hospitals

\begin{tabular}{|c|c|c|c|c|}
\hline $\begin{array}{l}\text { Area of } \\
\text { patient safety } \\
\text { culture }\end{array}$ & Dimension & $\begin{array}{l}\text { Mean } \\
(\%)\end{array}$ & $\begin{array}{l}\text { Standard } \\
\text { Deviation }\end{array}$ & $\begin{array}{l}\text { MPS } \\
\text { of area } \\
(\%)\end{array}$ \\
\hline \multirow{7}{*}{$\begin{array}{l}\text { (Unit-Level) } \\
\text { area of pa- } \\
\text { tient safety } \\
\text { culture }\end{array}$} & $\begin{array}{l}\text { Communication open- } \\
\text { ness } \\
\text { (3 questions) }\end{array}$ & 42.44 & 7.94 & \multirow{7}{*}{$53.7 \%$} \\
\hline & $\begin{array}{l}\text { Feedback and commu- } \\
\text { nication about error } \\
\text { ( } 3 \text { questions) }\end{array}$ & 56.10 & 15.57 & \\
\hline & $\begin{array}{l}\text { Supervisor/manager } \\
\text { expectations and actions } \\
\text { promoting safety ( } 4 \\
\text { questions) }\end{array}$ & 66.37 & 7.9 & \\
\hline & $\begin{array}{l}\text { Teamwork within the } \\
\text { unit } \\
\text { (4 questions) }\end{array}$ & 75.97 & 7.48 & \\
\hline & $\begin{array}{l}\text { Staffing } \\
\text { (4 questions) }\end{array}$ & 32.18 & 12.88 & \\
\hline & $\begin{array}{l}\text { Non-punitive response } \\
\text { to error } \\
\text { ( } 3 \text { questions) }\end{array}$ & 24.3 & 12.96 & \\
\hline & $\begin{array}{l}\text { Organizational learn- } \\
\text { ing-continuous im- } \\
\text { provement ( } 3 \text { questions) }\end{array}$ & 78.55 & 9.75 & \\
\hline \multirow{3}{*}{$\begin{array}{l}\text { (Hospital- } \\
\text { Wide) area } \\
\text { of patient } \\
\text { safety cul- } \\
\text { ture }\end{array}$} & $\begin{array}{l}\text { Executive management } \\
\text { support for patient } \\
\text { safety ( } 3 \text { questions) }\end{array}$ & 70.72 & 15.1 & \multirow{3}{*}{64.06} \\
\hline & $\begin{array}{l}\text { Teamwork across units } \\
\text { (4 questions) }\end{array}$ & 62.1 & 10.83 & \\
\hline & $\begin{array}{l}\text { Handoffs and transi- } \\
\text { tions between units and } \\
\text { shifts ( } 4 \text { questions) }\end{array}$ & 59.37 & 9.88 & \\
\hline \multirow{2}{*}{$\begin{array}{l}\text { (Outcome- } \\
\text { Measures) }\end{array}$} & $\begin{array}{l}\text { Overall perceptions of } \\
\text { safety } \\
\text { (4 questions) }\end{array}$ & 57.09 & 10.62 & \multirow{2}{*}{56.11} \\
\hline & $\begin{array}{l}\text { Frequency of error } \\
\text { reporting } \\
\text { (3 questions) }\end{array}$ & 55.13 & 10.23 & \\
\hline
\end{tabular}

Table 4: Descriptive Statistics of Total Outcome Measures for 12 Hospi-

\begin{tabular}{|c|c|c|c|}
\hline $\begin{array}{l}\text { Area of patient safety } \\
\text { culture }\end{array}$ & $\begin{array}{l}\text { Dimensions of } \\
\text { patient safety cul- } \\
\text { ture }\end{array}$ & MPS (\%) & \\
\hline \multirow{12}{*}{$\begin{array}{l}\text { (Outcome-Measures) } \\
\text { area of patient safety } \\
\text { culture }\end{array}$} & $\begin{array}{l}\text { Frequency of error } \\
\text { reporting } \\
\text { (3 questions) } \\
\text { Overall perceptions } \\
\text { of safety } \\
\text { (4 questions) }\end{array}$ & 55.13 & \\
\hline & \multirow{5}{*}{$\begin{array}{l}\text { Patient safety grade } \\
\text { (1 question) }\end{array}$} & Excellent & 7.87 \\
\hline & & Good & 40.73 \\
\hline & & Acceptable & 14.93 \\
\hline & & Bad & 28.46 \\
\hline & & Unacceptable & 7.61 \\
\hline & \multirow{6}{*}{$\begin{array}{l}\text { Number of events } \\
\text { reported } \\
\text { (1 question) }\end{array}$} & 0 & 49.4 \\
\hline & & $1-2$ & 32.3 \\
\hline & & $5-3$ & 11.1 \\
\hline & & $6-10$ & 1.3 \\
\hline & & $20-11$ & 2.7 \\
\hline & & $21 \leq$ & 3.2 \\
\hline
\end{tabular}

\subsection{Scores of PSC in psychiatric hospitals versus spe- cialized and general hospitals}

Among the three groups of hospitals, the highest percent of MPSs attributed to specialized hospitals with \%61.49. Psychiatric and general hospitals with $56.67 \%$ and $55.69 \%$ situated in a row after specialized hospitals. MPSs of PSC and respective standard deviations among the three groups of hospitals are represented in Table 5 .
Table 5: Total MPS of Patient Safety Culture and Respective Standard Deviations among the Three Groups of Hospitals

\begin{tabular}{|c|c|c|c|c|c|}
\hline Group & Hospital & $\begin{array}{l}\text { Patient } \\
\text { safety } \\
\text { culture } \\
\text { score }\end{array}$ & $\begin{array}{l}\text { Unit- } \\
\text { Level }\end{array}$ & $\begin{array}{l}\text { Hospital- } \\
\text { Wide }\end{array}$ & $\begin{array}{l}\text { Outcome- } \\
\text { Measures }\end{array}$ \\
\hline \multirow{7}{*}{$\begin{array}{l}\text { Psychi- } \\
\text { atric }\end{array}$} & Iran & $\begin{array}{l}\text { Mean=60 } \\
.97\end{array}$ & $\begin{array}{l}\text { Mean=61 } \\
.8\end{array}$ & $\begin{array}{l}\text { Mean=59 } \\
.41\end{array}$ & $\begin{array}{l}\text { Mean }=60 \\
.39\end{array}$ \\
\hline & Iranian & $\begin{array}{l}\text { Mean }=58 \\
.79\end{array}$ & $\begin{array}{l}\text { Mean=55 } \\
.4\end{array}$ & $\begin{array}{l}\text { Mean=67 } \\
.33\end{array}$ & $\begin{array}{l}\text { Mean }=57 \\
.87\end{array}$ \\
\hline & Roozbe & Mean $=49$ & Mean $=49$ & Mean $=45$ & Mean $=47$ \\
\hline & Mev- & Mean $=54$ & Mean $=47$ & Mean $=65$ & Mean $=60$ \\
\hline & manat & 61 & .41 & .8 & .75 \\
\hline & Total & Mean $=55$ & Mean $=53$ & Mean $=59$ & Mean $=56$ \\
\hline & $\begin{array}{l}\text { group } \\
\text { score }\end{array}$ & $\begin{array}{l}.84 \\
\mathrm{SD}=5.26\end{array}$ & $\begin{array}{l}.64 \\
S D=6.37\end{array}$ & $\begin{array}{l}.51 \\
\mathrm{SD}=9.94\end{array}$ & $\begin{array}{l}.72 \\
\mathrm{SD}=5.99\end{array}$ \\
\hline \multirow{5}{*}{ General } & $\begin{array}{l}\text { Bahar- } \\
\text { loo }\end{array}$ & $\begin{array}{l}\text { Mean=61 } \\
.59\end{array}$ & $\begin{array}{l}\text { Mean }=57 \\
.76\end{array}$ & $\begin{array}{l}\text { Mean }=73 \\
.16\end{array}$ & $\begin{array}{l}\text { Mean }=57 \\
.66\end{array}$ \\
\hline & Valiasr & $\begin{array}{l}\text { Mean }=53 \\
.9\end{array}$ & $\begin{array}{l}\text { Mean=52 } \\
.66\end{array}$ & $\begin{array}{l}\text { Mean }=61 \\
.66\end{array}$ & $\begin{array}{l}\text { Mean }=46 \\
.62\end{array}$ \\
\hline & $\begin{array}{l}\text { Firoozg } \\
\text { ar }\end{array}$ & $\begin{array}{l}\text { Mean }=57 \\
.01\end{array}$ & $\begin{array}{l}\text { Mean }=50 \\
.22\end{array}$ & $\begin{array}{l}\text { Mean }=70 \\
.27\end{array}$ & $\begin{array}{l}\text { Mean }=60 \\
.87\end{array}$ \\
\hline & Sina & $\begin{array}{l}\text { Mean }=67 \\
.97\end{array}$ & $\begin{array}{l}\text { Mean }=64 \\
.23\end{array}$ & Mean $=71$ & Mean $=72$ \\
\hline & $\begin{array}{l}\text { Total } \\
\text { group } \\
\text { score }\end{array}$ & $\begin{array}{l}\text { Mean=60 } \\
.11 \\
S D=6.11\end{array}$ & $\begin{array}{l}\text { Mean=56 } \\
.21 \\
S D=6.19\end{array}$ & $\begin{array}{l}\text { Mean=69 } \\
.02 \\
S D=5.05\end{array}$ & $\begin{array}{l}\text { Mean=59 } \\
.28 \\
S D=10.4 \\
4\end{array}$ \\
\hline \multirow{5}{*}{$\begin{array}{l}\text { Special- } \\
\text { ized }\end{array}$} & $\begin{array}{l}\text { Shafa } \\
\text { Ya- } \\
\text { hiaeian }\end{array}$ & $\begin{array}{l}\text { Mean=57 } \\
.5\end{array}$ & $\begin{array}{l}\text { Mean }=52 \\
.09\end{array}$ & $\begin{array}{l}\text { Mean=76 } \\
.47\end{array}$ & $\begin{array}{l}\text { Mean }=47 \\
.5\end{array}$ \\
\hline & $\begin{array}{l}\text { Motahh } \\
\text { ari }\end{array}$ & $\begin{array}{l}\text { Mean=62 } \\
.63\end{array}$ & $\begin{array}{l}\text { Mean=59 } \\
.89\end{array}$ & $\begin{array}{l}\text { Mean }=68 \\
.25\end{array}$ & $\begin{array}{l}\text { Mean }=63 \\
.62\end{array}$ \\
\hline & $\begin{array}{l}\text { Cancer } \\
\text { Institute }\end{array}$ & $\begin{array}{l}\text { Mean=46 } \\
.16\end{array}$ & $\begin{array}{l}\text { Mean }=46 \\
.17\end{array}$ & $\begin{array}{l}\text { Mean }=42 \\
.33\end{array}$ & $\begin{array}{l}\text { Mean=51 } \\
.87\end{array}$ \\
\hline & Arash & $\begin{array}{l}\text { Mean }=51 \\
45\end{array}$ & $\begin{array}{l}\text { Mean }=46 \\
04\end{array}$ & $\begin{array}{l}\text { Mean }=67 \\
58\end{array}$ & $\begin{array}{l}\text { Mean } \\
16\end{array}$ \\
\hline & $\begin{array}{l}\text { Total } \\
\text { group } \\
\text { score }\end{array}$ & $\begin{array}{l}\text { Mean=54 } \\
.43 \\
S D=7.16\end{array}$ & $\begin{array}{l}\text { Mean=51 } \\
.04 \\
S D=6.53\end{array}$ & $\begin{array}{l}\text { Mean=63 } \\
.65 \\
\mathrm{SD}=14.7 \\
8\end{array}$ & $\begin{array}{l}\text { Mean=52 } \\
.28 \\
\mathrm{SD}=7.93\end{array}$ \\
\hline
\end{tabular}

Table 6: MPSs in Each Dimension of Patient Safety Culture among the Three Groups of Hospitals

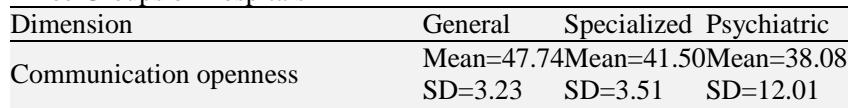

Feedback and communication about $\mathrm{Mean}=55.83 \mathrm{Mean}=46.16 \mathrm{Mean}=66.33$ error $\quad \mathrm{SD}=7.76 \quad \mathrm{SD}=15.89 \quad \mathrm{SD}=17.47$

Frequency of Error reporting $\quad M e a n=53.33 \mathrm{Mean}=51.66 \mathrm{Mean}=60.41$ $\mathrm{SD}=12.72 \quad \mathrm{SD}=8.71 \quad \mathrm{SD}=9.41$ Non-punitive response to error $\quad$ Mean=34.24Mean=23.66Mean=14.99 Organizational learning-contin improvement $\quad \mathrm{SD}=8.59 \quad \mathrm{SD}=13.55 \quad \mathrm{SD}=6.19$ Supervisor/manager expectations $\quad$ Mean=69.68Mean=63.00Mean=66.43 and actions promoting safety $\quad \mathrm{SD}=8.48 \quad \mathrm{SD}=10.89 \quad \mathrm{SD}=2.87$

Teamwork across units Mean $=63.37 \mathrm{Mean}=65.43 \mathrm{Mean}=57.50$ $\mathrm{SD}=10.51 \quad \mathrm{SD}=13.95 \quad \mathrm{SD}=8.96$ Mean $=73.81 \mathrm{Mean}=72.87 \mathrm{Mean}=81.25$

$\begin{array}{lll}\text { Teamwork within Unit } & \mathrm{Mean}=73.81 \mathrm{Mean}=72.87 \mathrm{Mean}=81.25 \\ \mathrm{SD}=5.91 \quad \mathrm{SD}=9.76 \quad \mathrm{SD}=4.34\end{array}$ Executive management support for $\mathrm{Mean}=78.58 \mathrm{Mean}=70.41 \mathrm{Mean}=63.16$ patient safety $\quad \mathrm{SD}=6.43 \quad \mathrm{SD}=22.27 \quad \mathrm{SD}=11.86$

Overall perception of safety $\quad$ Mean $=65.25 \mathrm{Mean}=53.00 \mathrm{Mean}=53.03$ $\mathrm{SD}=10.00 \quad \mathrm{SD}=11.29 \quad \mathrm{SD}=7.28$

Hand-offs and Transitions between Mean=65.12Mean=55.12Mean=57.87 units $\mathrm{SD}=4.87 \quad \mathrm{SD}=11.34 \quad \mathrm{SD}=11.60$ Mean $=32.56 \mathrm{Mean}=36.75 \mathrm{Mean}=27.25$ Staffing $\mathrm{SD}=11.85 \quad \mathrm{SD}=18.46 \quad \mathrm{SD}=8.18$

The highest MPSs in psychiatric hospitals includes $82.33 \%$ "Organizational learning-continuous improvement", $81.25 \%$ "Teamwork within Unit", and 66.43\% "Supervisor/manager expectations and actions promoting safety" which situated this group of hospitals in the very strong position at the first two named dimension and in the strong position for the last one. The lowest MPSs were $14.99 \%$ "Non-punitive response to error", 27.25\% "Staffing", and $38.08 \%$ "Communication openness" locating the first one in the 
very weak area and the second two mentioned dimensions in the weak area of the cut points. Table 6 reveals MPSs in each dimension of PSC in psychiatric hospitals.

In psychiatric hospitals $41.11 \%$ of the participants considered patient safety grad acceptable and $27.77 \%$ of respondents articulated that any adverse event or error have not been reported by them in past 12 months. Frequencies of outcome measures (the grade of hospitals' patient safety expressed by personnel=E1 and the percent of personnel which not reported any medical error in one year=G1) in psychiatric hospitals are available in Table 7 .

Table 7: The Most Frequent Answers for E1 and G1 (\%)

\begin{tabular}{lll}
\hline Hospital Group & E1 & G1 \\
\hline Psychiatric & 41.11 (acceptable) & 27.77 \\
Specialized & 52.2 (strong) & 60 \\
General & 47.31 (strong) & 56.98 \\
Total & 40.2 (strong) & 49.3 \\
\hline
\end{tabular}

The highest specialized hospitals' percent of MPSs included 73.66 "Organizational learning-continuous improvement", 72.87 "Teamwork within Unit", and 70.41 "Executive management support for patient safety" locating them in the strong position. The lowest MPSs were 23.66 "Non-punitive response to error", 36.75 "Staffing", and 41.5 "communication openness" situating the first two in the weak spot in the cut points and the last one in the average position. Mean and SD of MPSs in each dimension of PSC in specialized hospitals represents in Table 7.

In specialized hospitals, $52.2 \%$ of Respondents expressed that the grade of patient safety was strong and $\% 60$ have not reported any error or adverse event to their superior authority in past 12 months. Frequencies of outcome measures in specialized hospitals are revealed in table 8 .

The highest MPSs among general hospitals comprised: $79.66 \%$ "Organizational learning-continuous improvement", 78.58\% "Executive management support for patient safety", and $73.81 \%$ "Teamwork within Unit" respectively which established them in the strong area of the cut points in the named dimensions. The lowest MPSs among general hospitals include $32.56 \%$ "Staffing", $34.24 \%$ "Non-punitive response to error", and $47.74 \%$ "communication openness" locating this group of hospital in the weak area of the cut points in the first two named dimensions and in the average position with respect to the last dimension. Table 7 provides MPSs in each dimension of PSC in general hospitals.

Regarding patient safety grade, $47.31 \%$ believes that very strong was the position of general hospitals and $56.98 \%$ of the participants claimed that they have not reported any adverse events or medical errors in the past 12 months. Frequencies of outcome measures in general hospitals are available in table 8 .

\subsection{Comparison of safety culture dimensions among various groups of hospitals}

The differences among the three groups dimensions' MPS allied to PSC were analyzed by employing one-way ANOVA analysis and Tukey's HSD. Results of ANOVA analysis revealed that there are no significant differences between dimensions of the three groups of study sample. Results of ANOVA analysis overall MPSs exposed the fact that there are no significant differences among the three groups of hospitals $(\mathrm{P}<0.05)$. Similarly, have not been emerged any significant differences out of Tukey's HSD test pertain to MPSs $(\mathrm{P}<0.05)$.

\section{Discussion}

The most striking observation to emerge from the data comparison was absence of significant differences neither in the sum total of MPS among the three groups of hospitals nor in 12 dimensions of PSC questionnaire (HSOPSC). These findings would seem to imply that within a psychiatric hospital considering its unique condition regarding safety and security in comparison with other two groups and a critical/intensive care unit in specialized hospital having a high workload and heavy job pressure on its personnel PSC have been perceived and implemented similarly which delineates an enormous gap correspond with safety culture since there are some fundamental disparity given PSC amongst these three type of hospitals in which clinicians deliver care [31] [32] [34].

Another key finding at this study allude to a general weakness allied with PSC between the three groups of hospitals in our study and other Middle East countries which our results showed mean scores of Middle East PSC are superior in all of the 12 dimensions of PSC [54] [55].

In the Psychiatric hospitals the strongest dimensions of PSC included: Organizational learning-continuous improvement, and Teamwork within Unit, in the specialized group the strongest dimensions were exactly the same as Psychiatric while in the Generals organizational learning-continuous improvement and Executive management support for patient safety fulfilled as the strongest dimensions. Thus in the three groups of our study the strongest dimensions were virtually similar.

With regard to the weakest dimensions among the three groups, it was revealed that they were equal comprising: Non-punitive response to error, staffing, and communication openness. Contrary to expectations, our results express that there is an almost exact similar weaknesses and strengths among the three types of hospital in this study.

In other domestic similar studies the strongest dimensions identified as Organizational learning-continuous improvement, and Teamwork within Unit and the weakest recognized as Nonpunitive response to error, staffing, communication openness, frequency of error reporting, and management support for patient safety, supporting our results pertains to strongest and weakest dimensions, suggesting that Iran's hospitals dealing with identical problems concerning PSC [54] [56] [57].

In Middle East countries the strongest dimensions includes: Teamwork within Unit, Supervisor/manager expectations and actions promoting safety, Organizational learning-continuous improvement, and Executive management support for patient safety. Non-punitive response to error, staffing, and Hands-off and Transitions between units were identified as the weakest dimensions in the Middle East countries [55] [54]. Listed findings is in complete agreement with our results so that, all of the strengths and weaknesses emerged in the mentioned study are equal to ours. It is necessary to mention that most of the PSC dimensions scores within the three groups of hospitals were in weak and average position thus they ask for a stiff consideration in PSC practices of organizations internally and externally. Instead, we considered the weakest dimensions asking for an urgent reformation which if they were not rapidly modified, PSC in Iran may always remain an unsolvable issue. Scores which located in the same area of cutpoints implicate that dimensions in one hospital or among hospitals fulfilled degree in PSC is the same, although they may be higher in little extent.

\subsection{Non-punitive response to error}

Several factors affect on this dimension among which attitude, believes, and behaviors of organizations' CEOs and also supervisor organizations (University of medical science and Ministry of health affairs) pertains to the way of responding to error and medical events can be blamed as the most effective factor. All the more reason for creating this wrong culture was inappropriate behaviors and retorting as soon as confronting to an error without digging deep for a root cause. Consequently, ignorance toward solving the root causes and afterwards, decreasing of service quality in numerous health systems has been arising for decades [56].

In this respect, providing we draw our attention to hospital as a system in which hundreds of people and process are closely intertwined, it could be fathom that a collection of factors should stand in one direction so that, a complex process of error happens. Given that, as a matter of fact events will not happen if the factors were curbed to stand simultaneously in the same track of creating 
an event from different directions. Furthermore, suitable design of hospitals' structure involving in the care process could be the most preventive precaution to take in order to stop medical errors [56] [58] [59].

The most significant factors aiming for rectifying the culture of punitive response to medical error include: culture of team work, educational perspective about every single medical event and considering it as an opportunity by which organizational weaknesses will be found and solved, eradicating fear of being blamed or expecting bad consequences following from error reporting through deep searching and using of root analysis technics, establishing an integrated system, not a person, with the purpose of investigating medical events within hospital, shifting mind framework of CEOs and clinical managers from this falls thought that punishment and reproach delinquent personnel would imply that they are responsible about patient safety issues [60] [56] [54] [55].

Accompanying with the idea that "human error is inevitable" (Bahrami, 2013, p.646), distance managers from interrogating personnel like a criminal and blaming them and transfers authorities to search for deficiency through processes, equipment, and in sum total the system of hospital [54] [61] [58]. Establishing an encouraging atmosphere with the aim that reporting errors from which learning process happens, not only bring any fear neither for reporter of the event nor for the main person in the process of event but so also stimulate personnel toward sharing and learning from medical events in the healthcare organization so that PSC experiment a massive growth in its pathway [57].

\subsection{Staffing}

Inadequacy of staff is in a great contrast with high pressure of demands in public hospitals particularly teaching ones in which a high amount of budget is allocated to education, whereas it could have been spent on recruiting with the intention of compensating the shortage of professionals [54]. Long stand of personnel in their shifts, so that they can offset the shortage of workforce, have been led to escalate work hours in as far as more than $\% 50$ of clinicians, especially nurses, work more than 40 hours per week. Hence, staff have been working in crisis situations (always doing something which is more than your ability in a very fast way) for a long time [62]. As a result, contingency of medical errors arose and quality of health services declined [54] [62] [63]. Considering a certain amount of investment in planning and promotion regarding staffing seems indispensible. In addition, initiation of remedial schemes given staffing in the strategic plan of hospital and supervisor organizations (university of medical sciences and ministry of health) is vitally important in the way of curbing shortage of workforce as a perennial obstacle [57].

\subsection{Communication openness}

One of the weaknesses obviously recognizing in this research was a general weakness in freedom of expression and talking freely by personnel about their concerns pertaining to patient safety. Increase of medical events fallows from lack of supportive atmosphere of expressing ideas and worries which not only have not been encouraged by supervisors and top managers of the organization, but also they have been treated with negative behaviors such as humiliation, insult, and rage [46] [57]. Clinicians as the straight care providers face to lots of issues, significant or marginal, which they might be barriers for protection of patients from hazardous hospitals' environment. Given that, in addition to prevent medical events, it could obtain an opportunity for learning and promoting patient safety in organization. In this regard, a deep trust and reliance should be established between personnel and their managers which is only the duty of top managers in every health care organization. This bridge of trust will encourage clinicians in order to speak up about their ideas regarding safety when confront with a situation that makes them anguish. Additionally, this bridge invites them to share their opinions and suggestions promoting patient safety [64] [57].

\subsection{Error reporting}

Rate of error reporting in general and psychiatric groups of hospitals shows a comparative weakness because of the fact that more than half of personnel in both groups did not report any medical event in one year. Various factors and elements can cause absence of tendency toward error reporting including: awareness of patients about their rights within a health system [55] [65], existence of reporting mechanisms and the knowledge of its modus operandi in personnel [55] [56] [65], transparency in need and necessity of reporting an event [55] [65], communication failure [60] [65] [66], time-consuming process of reporting [55] [65], lack of feedback relative to reports or delay within giving feedback to reporter or the system who is responsible for investigating about reports [58] [55] [60], failure and inability of individual or systems responsible for attending errors to clarify and identify root causes of errors [58 [54] [67] [55] [56], and finally, atmosphere of punishment and blame with regard to errors which is directly allude to hospitals' top managers and health policy makers. [67] [54] [62] [55] [56] [58]. Health provider organizations' managers must make vast efforts in order that a supportive atmosphere for error reporting is established within an organization. Along with that, launching an integrated reporting system so as to identify defects of system, making error reporting a purposeful process, and delivering on time feedbacks would seems to be necessary. This common language accompanying with weekly arranged meetings aiming to review medical errors and root analyzing in order for identifying the main causes and factors relating to events, will contribute to a great stark in error reporting condition in health systems [60] [55].

\section{Conclusion}

Iran's hospitals seem to be lagged behind the rest of Middle East countries concerning the patient safety issues. The results of PSC assessment in the current study among three types of care giver revealed that contrary to our supposition, there is not any significant differences among the three groups pertains to PSC. The weakest dimensions of PSC, demanding for an urgent reinforcement, in this study included "Non-punitive response to error", "Staffing", "Communication openness", and "Frequency of error reporting" achieving to very weak grade among the study categorization of cut points. Systematic thinking and considering patient safety issues as an opportunity through which personnel can be learnt safety lessons are remedies to Iranian hospitals. In addition, patient safety should be penetrated into hospitals' and supervisor organizations' strategic plans. On the other hand, psychiatric hospitals/ wards and critical/intensive care units must state in the highest priority of strategic plans in compare with other types of hospitals/wards with respect to their particular nature. Against of our hypothesis have not been found any significant differences between the three groups of hospitals in our study which may allude to the point that culture mostly is to be local than various among different care specialties. This paper has highlighted that Iran's hospitals have achieved a lower degree of PSC in compare with Middle East countries which allude to a deep gap given this fundamental issue to which need to attend by health care politicians.

\section{References}

[1] LT. Kohn, JM. Corrigan, MS. Donaldson, To Err Is Human: Building a Safer Health System, National Academies Press, 2000.

[2] S. Singer, S. Lin, A. Falwell, D. Gaba, L. Baker, Relationship of safety climate and safety performance in hospitals, Health services research 44 (2009) 399-421. http://dx.doi.org/10.1111/j.14756773.2008.00918.x

[3] S. Clarke, Safety culture: under-specified and overrated?, International Journal of Management Reviews 2 (2000) 65-90. http://dx.doi.org/10.1111/1468-2370.00031.

[4] Mg. Milczarek, A. Najmiec, The Relationship Between Workers' Safety Culture and Accidents, Near Accidents and Health 
Problems, International Journal of Occupational Safety and $\begin{array}{llll}\text { Ergonomics } & 10 & \text { (2004) } & \text { 25-33 }\end{array}$ http://dx.doi.org/10.1080/10803548.2004.11076592.

[5] R. Flin, Measuring safety culture in healthcare: A case for accurate diagnosis, Safety Science 45 (2007) 653-67. http://dx.doi.org/10.1016/j.ssci.2007.04.003.

[6] Y. Pfeiffer, T. Manser, Development of the German version of the Hospital Survey on Patient Safety Culture: Dimensionality and psychometric properties, Safety Science 48 (2010) 1452-62. http://dx.doi.org/10.1016/j.ssci.2010.07.002.

[7] D. Zohar, Thirty years of safety climate research: Reflections and future directions, Accident Analysis \& Prevention 42 (2010) 1517 22. http://dx.doi.org/10.1016/j.aap.2009.12.019.

[8] DL. Phipps, DM. Ashcroft, An investigation of occupational subgroups with respect to patient safety culture, Safety Science 50 (2012) 1290-8. http://dx.doi.org/10.1016/j.ssci.2011.12.016.

[9] S. Silva, ML. Lima, C. Baptista, OSCI: an organisational and safety climate inventory, Safety science 42 (2004) 205-20. http://dx.doi.org/10.1016/S0925-7535(03)00043-2.

[10] RR. Gershon, CD. Karkashian, JW. Grosch, LR. Murphy, A. Escamilla-Cejudo, PA. Flanagan, et al., Hospital safety climate and its relationship with safe work practices and workplace exposure incidents, American journal of infection control 28 (2000) 211-21. http://dx.doi.org/10.1067/mic.2000.105288.

[11] D. McCarthy, D. Blumenthal, Stories from the sharp end: case studies in safety improvement, Milbank Quarterly 84 (2006) 165200. http://dx.doi.org/10.1111/j.1468-0009.2006.00442.x.

[12] HSE, Reducing error and influencing behaviour, Health and Safety Executive, 2009.

[13] MP. Aust, Establishing a Culture of Safety, American Journal of Critical Care 22 (2013) 104. http://dx.doi.org/10.4037/ajcc2013506.

[14] R. Agarwal, S. Chaturvedi, N. Chhillar, I. Pant, S. Kaushik, CB Tripathi, A Trend Analysis of Quality Indicators of Patient Safety in the Clinical Laboratory Over 21 Months, Lab Medicine 43 (2012) 300-6. http://dx.doi.org/10.1309/LM37GO5GCSZYOZSA

[15] AJ. Leendertse, AC. Egberts, LJ. Stoker, PM. van den Bemt, Frequency of and risk factors for preventable medication-related hospital admissions in the Netherlands, Archives of internal medicine 168 (2008) 1890-6.

[16] M. Zegers, M. De Bruijne, C. Wagner, L. Hoonhout, R. Waaijman, M. Smits, et al., Adverse events and potentially preventable deaths in Dutch hospitals: results of a retrospective patient record review study, Quality and Safety in Health Care 18 (2009) 297-302. http://dx.doi.org/10.1136/qshc.2007.025924.

[17] AB. Haynes, TG. Weiser, WR. Berry, SR. Lipsitz, A-HS. Breizat, EP. Dellinger, et al., Changes in safety attitude and relationship to decreased postoperative morbidity and mortality following implementation of a checklist-based surgical safety intervention, $\begin{array}{llllll}\text { BMJ quality \& safety } 20 & \text { (2011) } & 102-7\end{array}$ http://dx.doi.org/10.1136/bmjqs.2009.040022.

[18] A. Okuyama, K. Martowirono, B. Bijnen, Assessing the patient safety competencies of healthcare professionals: a systematic review, BMJ quality \& safety qhe (2011) 000148

[19] RE. Mardon, K. Khanna, J. Sorra, N. Dyer, T. Famolaro, Exploring relationships between hospital patient safety culture and adverse events, Journal of patient safety 6 (2010) 226-32 http://dx.doi.org/10.1097/PTS.0b013e3181fd1a00.

[20] PJ. Pronovost, CA. Goeschel, JA. Marsteller, JB. Sexton, JC. Pham, SM. Berenholtz, Framework for patient safety research and $\begin{array}{llll}\text { improvement, } & \text { Circulation } & 119 & \text { (2009) }\end{array} 330-7$. http://dx.doi.org/10.1161/CIRCULATIONAHA.107.729848.

[21] C. Snijders, BJ. Kollen, RA. van Lingen, WP. Fetter, H. Molendijk, NS. Group, Which aspects of safety culture predict incident reporting behavior in neonatal intensive care units? A multilevel analysis, Critical care medicine 37 (2009) 61-7. http://dx.doi.org/10.1097/CCM.0b013e31819300e4

[22] S. Kirk, D. Parker, T. Claridge, A. Esmail, M. Marshall, Patient safety culture in primary care: developing a theoretical framework for practical use, Quality and Safety in Health Care 16 (2007) 31320. http://dx.doi.org/10.1136/qshc.2006.018366.

[23] C. Wagner, R. Mannion, A. Hammer, O. Groene, O. Arah, M. Dersarkissian, et al., The associations between organizational culture, organizational structure and quality management in European hospitals, International Journal for Quality in Health Care mzu (2014) 027.

[24] S. Clarke, The relationship between safety climate and safety performance: a meta-analytic review, Journal of occupational health psychology $11 \quad$ (2006) 315. http://dx.doi.org/10.1037/10768998.11.4.315.
[25] E. Knebel, AC. Greiner, Health Professions Education: A Bridge to Quality, National Academies Press 2003.

[26] Nursing AaoCo, The essentials of baccalaureate education for professional nursing practice, 2008.

[27] B. Flanagan, D. Nestel, M. Joseph, Making patient safety the focus: crisis resource management in the undergraduate curriculum, $\begin{array}{llll}\text { Medical education } & 38 & \text { (2004) } & 56-66\end{array}$ http://dx.doi.org/10.1111/j.1365-2923.2004.01701.x.

[28] D. Mayer, DL. Klamen, A. Gunderson, P. Barach, Designing a patient safety undergraduate medical curriculum: the Telluride Interdisciplinary Roundtable experience, Teaching and learning in $\begin{array}{lll}\text { medicine } & 21 & \text { (2009) }\end{array}$ http://dx.doi.org/10.1080/10401330802574090.

[29] A. Wakefield, M. Attree, I. Braidman, C. Carlisle, M. Johnson, H. Cooke, Patient safety: do nursing and medical curricula address this theme?, Nurse education today 25 (2005) 333-40 http://dx.doi.org/10.1016/j.nedt.2005.02.004.

[30] DS. Debono, D. Greenfield, JF. Travaglia, JC. Long, D. Black, J. Johnson, et al., Nurses' workarounds in acute healthcare settings: a scoping review, BMC health services research 13 (2013) 175 . http://dx.doi.org/10.1186/1472-6963-13-175.

[31] D. Raveendranathan, PS. Chandra, SK. Chaturvedi, Violence among psychiatric inpatients: A victim's perspective, East Asian archives of psychiatry 22 (2012) 141.

[32] H. Gilburt, D. Rose, M. Slade, The importance of relationships in mental health care: A qualitative study of service users' experiences of psychiatric hospital admission in the UK, BMC Health Services Research 8 (2008) 92. http://dx.doi.org/10.1186/1472-6963-8-92.

[33] S. Berenholtz, T. Dorman, P. Pronovost, Improving quality and safety in the ICU, Contemp Crit Care 1 (2003) 1-10.

[34] LD. Scott, AE. Rogers, W-T. Hwang, Y. Zhang, Effects of critical care nurses' work hours on vigilance and patients' safety, American Journal of Critical Care 15 (2006) 30-7.

[35] S. Osmon, CB. Harris, WC. Dunagan, D. Prentice, VJ. Fraser, MH. Kollef, Reporting of medical errors: an intensive care unit experience, Critical care medicine 32 (2004) 727-33. http://dx.doi.org/10.1097/01.CCM.0000114822.36890.7C

[36] AI. Glendon, NA. Stanton. Perspectives on safety culture, Safety Science 34 (2000) 193-214. http://dx.doi.org/10.1016/S0925 7535(00)00013-8.

[37] FW. Guldenmund, The nature of safety culture: a review of theory and research, Safety science 34 2000) 215-57. http://dx.doi.org/10.1016/S0925-7535(00)00014-X

[38] A. Hutchinson, K. Cooper, J. Dean, A. McIntosh, M. Patterson, C. Stride, et al., Use of a safety climate questionnaire in UK health care: factor structure, reliability and usability, Quality and Safety in $\begin{array}{llll}\text { Health Care } & 15 & \text { (2006) } & 347-53 .\end{array}$ http://dx.doi.org/10.1136/qshc.2005.016584.

[39] DL. Zwart, M. Langelaan, RC. van de Vooren, MM. Kuyvenhoven, CJ. Kalkman, TJ. Verheij, et al., Patient safety culture measurement in general practice, Clinimetric properties of'SCOPE', BMC family practice 12 (2011) 117. http://dx.doi.org/10.1186/1471-2296-12117.

[40] JR. Frank, S. Brien, The safety competencies: enhancing patient safety across the health professions, Canadian Patient Safety Institute= Institut canadien pour la sécurité 2008 .

[41] M. Walton, H. Woodward, S. Van Staalduinen, C. Lemer, F. Greaves, D. Noble, et al., The WHO patient safety curriculum guide for medical schools, Quality and Safety in Health Care 19 (2010) 542-6. http://dx.doi.org/10.1136/qshc.2009.036970.

[42] J. Sorra, VF. Nieva, Hospital survey on patient safety culture, Agency for Healthcare Research and Quality 2004.

[43] H. Alahmadi, Assessment of patient safety culture in Saudi Arabian hospitals, Quality and Safety in Health Care 19 (2010) $1-5$ http://dx.doi.org/10.1097/QMH.0b013e3181d1391c.

[44] F. El-Jardali, M. Jaafar, H. Dimassi, D. Jamal, R. Hamdan, The current state of patient safety culture in Lebanese hospitals: a study at baseline, International Journal for Quality in Health Care mzq (2010) 047

[45] J. Hellings, W. Schrooten, N. Klazinga, A. Vleugels, Challenging patient safety culture: survey results, International journal of health $\begin{array}{llll}\text { care quality assurance } 20 & \text { (2007) 620-32. }\end{array}$ http://dx.doi.org/10.1108/09526860710822752.

[46] J. Kim, K. An, MK. Kim, SH. Yoon, Nurses' perception of error reporting and patient safety culture in Korea, Western Journal of $\begin{array}{llll}\text { Nursing } & \text { Research } & 29 & \text { (2007) }\end{array}$ http://dx.doi.org/10.1177/0193945906297370.

[47] SJ. Singer, D. Gaba, J. Geppert, A. Sinaiko, S. Howard, K. Park, The culture of safety: results of an organization-wide survey in 15 
California hospitals, Quality and safety in health care 12 (2003) 112-8. http://dx.doi.org/10.1136/qhc.12.2.112.

[48] MJC. Grant, AE. Donaldson, GY. Larsen, The safety culture in a children's hospital, Journal of nursing care quality 21 (2006) 223-9. http://dx.doi.org/10.1097/00001786-200607000-00006.

[49] J. Hellings, W. Schrooten, NS. Klazinga, A. Vleugels, Improving patient safety culture, International journal of health care quality $\begin{array}{llll}\text { assurance } & 23 & \text { (2010) }\end{array}$ http://dx.doi.org/10.1108/09526861011050529.

[50] IC. Chen, HH. Li, Measuring patient safety culture in Taiwan using the Hospital Survey on Patient Safety Culture (HSOPSC), BMC $\begin{array}{lllll}\text { Health Services } & \text { Research } 10 \quad \text { (2010) }\end{array}$ http://dx.doi.org/10.1186/1472-6963-10-152.

[51] D. Ausserhofer, M. Schubert, S. Engberg, M. Blegen, G. De, R. Schwendimann, Nurse-reported patient safety climate in Swiss hospitals: a descriptive-explorative substudy of the Swiss RN4CAST study, Swiss medical weekly 142 (2011) 0-.

[52] R. Ballangrud, B. Hedelin, ML. Hall-Lord, Nurses' perceptions of patient safety climate in intensive care units: A cross-sectional study, Intensive and Critical Care Nursing 28 (2012) 344-54. http://dx.doi.org/10.1016/j.iccn.2012.01.001.

[53] M. Javad, G. Amin, M. Mahbobe, R. Forooshani, ASA. Abas, A. Mohammad. Validation of Farsi version of hospital survey on patient Safety culture questionnaire, using confirmatory factor analysis method, Hospital Journal 11 (2012).

[54] MA. Bahrami, R. Montazeralfaraj, M. Chalak, AD. Tafti, GA Tehrani, SE. Ardakani, Patient Safety Culture Challenges: Survey Results of Iranian Educational Hospitals, Middle-East Journal of Scientific Research 14 (2013) 641-9.

[55] K. Henriksen, JB. Battles, MA. Keyes, ML. Grady, KJ. Jones, A Skinner, et al., The AHRQ hospital survey on patient safety culture: a tool to plan and evaluate patient safety programs 2008 .

[56] N. Hatam, V. Keshtkar, F. Forouzan, P. Bastani, Patient Safety Culture Status in Teaching Hospitals: A Case of Shiraz University of Medical Sciences, Middle-East Journal of Scientific Research 12 (2012) 970-5.

[57] A. Mohammadreza, T. Sogand, B. Omid, Measuring safety culture and setting priorities for action at an Iranian hospital, Al Ameen J Med Sci 3 (2010) 237-45.

[58] GD. Dalton, XF. Samaropoulos, AC. Dalton, Improvements in the safety of patient care can help end the medical malpractice crisis in the United States, Health policy 86 (2008) 153-62. http://dx.doi.org/10.1016/i.healthpol.2007.10.005.

[59] S. Keady, M. Thacker, National Patient Safety Agency: Improving patient safety across all critical care areas, Intensive and Critical Care Nursing $24 \quad$ (2008) 137-40. http://dx.doi.org/10.1016/j.iccn.2007.08.006.

[60] H. Jasti, H. Sheth, M. Verrico, S. Perera, G. Bump, D. Simak, et al., Assessing patient safety culture of internal medicine house staff in an academic teaching hospital, Journal of graduate medical education 1 (2009) 139-45. http://dx.doi.org/10.4300/01.01.0023.

[61] DM. Elston, E. Stratman, H. Johnson-Jahangir, A. Watson, S Swiggum, CW. Hanke, Patient safety: Part II. Opportunities for improvement in patient safety, Journal of the American Academy $\begin{array}{llll}\text { of Dermatology } & 61 & \text { (2009) }\end{array}$ http://dx.doi.org/10.1016/j.jaad.2009.04.055.

[62] M. Hamdan, AAo. Saleem, Assessment of patient safety culture in Palestinian public hospitals, International journal for quality in $\begin{array}{llll}\text { health } & \text { care } & 25 & \text { (2013) }\end{array}$ http://dx.doi.org/10.1093/intqhc/mzt007.

[63] SM. Keller, Effects of extended work shifts and shift work on patient safety, productivity, and employee health, AAOHN journal: official journal of the American Association of Occupational Health Nurses 57 (2009) 497-502; quiz 3-4.

[64] LL. Leape, DM. Berwick, Five years after To Err Is Human: what have we learned?, Jama 293 (2005) 2384-90. http://dx.doi.org/10.1001/jama.293.19.2384.

[65] CL. Uribe, SB. Schweikhart, DS. Pathak, GB. Marsh, RR. Fraley, Perceived barriers to medical-error reporting: an exploratory investigation, Journal of Healthcare Management 47 (2002) 263.

[66] LI. Horwitz, HM. Krumholz, ML. Green, SJ. Huot, Transfers of patient care between house staff on internal medicine wards: a national survey, Archives of internal medicine 166 (2006) 1173-7. http://dx.doi.org/10.1001/archinte.166.11.1173.

[67] BJ. Weiner, C. Hobgood, MA. Lewis, The meaning of justice in safety incident reporting, Social science \& medicine 66 (2008) 403 13. http://dx.doi.org/10.1016/j.socscimed.2007.08.013. 